\title{
THE EVOLUTIONARY DIFFERENTIATION OF STRIDULATORY SIGNALS IN BEETLES (Insecta: Coleoptera)
}

\author{
BY RICHARD D. ALEXANDER AND THOMAS E. MOORE \\ Museum of Zoology and Department of Zoology, The University of Michigan, Ann Arbor \\ AND ROBERT E. WOODRUFF \\ Florida Department of Agriculture, Division of Plant Industry, Gainesville
}

\section{Introduction}

Stridulatory noises have been discussed for many different families of beetles, and presumed stridulatory organs have been described for hundreds of species that have not actually been heard stridulating. (cf. Arrow, 1904, and bibliography by Frings \& Frings 1960). So far, neither auditory organs nor acoustical functions have been experimentally demonstrated in any beetle. There are a few records of beetles stridulating upon contact with other individuals of their own species (Liles, 1956; Alexander, 1957), but otherwise, only gross disturbances, e.g. handling or restraint, have been observed to elicit stridulation.

As a more or less incidental adjunct to investigations on the acoustical behaviour of Orthoptera, Homoptera, and Hemiptera by Alexander \& Moore, and as a result of the particular efforts and interest of Woodruff, we have accumulated tape-recordings of about 40 beetle species in eight families; Passalidae, Trogidae, Scarabaeidae, Chrysomelidae, Tenebrionidae, Carabidae, Curculionidae, and Cerambycidae. In this paper we compare disturbance stridulation among congeneric, sympatric species in two subsocial families (Trogidae and Scarabaeidae) and one non-social family (Cerambycidae), and discuss two new kinds of beetle stridulations: a "spontaneous" stridulation in isolated, undisturbed Trogidae and a distinctive aggressive stridulation in the social Passalidae. All of these sounds taken together appear to illustrate three stages in the evolutionary elaboration of communicative signals: (1) a single structural kind of signal utilized in a single functional context (disturbance-actual function not proven); (2) a single structural kind of signal utilized in two different functional contexts (disturbance and calling, disturbance and congregation, and possibly disturbance and some sort of "recognition"); and (3) two structurally different signals utilized in two different functional contexts (disturbance and aggression).
"Spontaneous" Stridulation in Trogidae

While collecting at night with headlamps on 16th May, 1959, in Ripley County, Missouri, we heard chirping coming from the ground around a dead cat lying in a sparsely vegetated area along the roadside. Using a portable tape recorder, earphones, and a microphone to amplify and localize the sounds, we found that chirping came from several burrows, each about $8 \mathrm{~mm}$. diameter, which were scattered within a few feet of the carcass. The burrows were about 10 centimetres deep and nearly vertical; each of several excavated contained one adult female of Trox suberosus Fabricius at its lower end. One burrow contained a male and a female; it is not known whether sound was coming from this particular burrow.

The sound was a continual irregular, repeating of the phrases shown in Fig. 1. Each phrase was produced by one stroke of a small ridge (plegmatium) on the dorsal surface of the abdomen across two tooth-like ridges (files) on the underside of the elytra. The file (Figs. 18 and 19) covers approximately the posterior one-third of the length of the elytra and is composed of over 150 teeth in a very narrow strip running parallel to the suture on a raised carina. The teeth in the middle of the ridge are slightly more widely separated than those on either end but they are all minute and difficult to detect except under high magnification (60X). Sharp (1897) described similar stridulatory apparatus in several Trox species. During stridulation the abdomen is moved up and down and slightly forward and backward to engage the plegmatium (Fig. 16) with the file. This movement is not extensive but is easily observed. Apparently only a portion of the narrow file is struck on each movement, since a maximum of twenty tooth strikes is eindicated on the audiospectrograph.

The beetles (both sexes) produced essentially the same sound when captured (Fig. 2), and when isolated overnight in vials and left undisturbed. Some individuals produced this 
sound continually for very long periods of time while lying otherwise motionless on their backs. Using the amplifier of a tape recorder as a monitor, we found that some beetles were still stridulating hours after being isolated in padded chambers completely separated from any reasonable possibility of external disturbances. *

To our knowledge there is no previously recorded instance of a beetle producing a stridulatory sound in the absence of disturbance by other animals. In other disturbed beetles that we have recorded, the stridulation always stopped a few seconds after the disturbance was discontinued. In the particular case of Trox suberosus, even if stridulation in the burrows was initiated by our footsteps-unlikely because we were several yards away and motionless when the chirps were first noticed-it continued during several long periods when we were providing no disturbance at all, and it was delivered at the same tempo regardless of our activities.

The "spontaneous" stridulation of Trox suberosus can be analogized with the calling and congregating noises of male Orthoptera and Homoptera, often termed spontaneous, not so much because of the kind of initiating stimulus, but because once started they continue for long periods unless disturbances cause their cessation. Although the thresholds for the production of such sounds can be adjusted by different events -for example, changes in light intensity (Alexander, 1960) and the presence or absence of a spermatophore in the spermatophore pouch in Orthoptera (Huber, 1960)-it is not known whether any of them are ever initiated in a normal animal without external stimulation; in fact, without external acoustical stimulation of one sort or another. We have not yet satisfactorily answered the ancient question: "What makes the cricket chirp?"

"Spontaneous" or long-continued sound production could evolve from any kind of signal requiring a specific and more or less continual stimulation through: (1) a lowering of threshold with respect to the required intensity or specificity of the external initiating stimuli and (2) a tendency to continue the reaction after the initiating stimulus has disappeared. The latter can be effected through auditory feedback, through

\footnotetext{
*All sounds were recorded with a Magnemite Portable Tape Recorder, Model 610-E, or a Magnecorder, Model PT63AH, and a D-33 American Dynamic Microphone, at a tape speed of 15 inches per second. Specimens and tape recordings are located in the University of Michigan Museum of Zoology.
}

proprioceptive feedback, or through rhythms inherent in the make-up of the central nervous system. Trox suberosus may represent an intermediate stage in the divorcement of a sound from its old stimulus situation (probably disturbance) as a result of its having acquired a new function. The situation here suggests that the continual chirping may attract males into the female's burrow, or deter other females from entering occupied burrows, or do both. Each burrow was undoubtedly destined to become the home of one pair of these sub-social beetles and their off-spring.

\section{Aggressive and Other Stridulations in Passalidae}

There is little doubt that sound has acquired a congregating function in the social Passalidae, where larvae have evolved the ability to produce a sound similar to that of the adults by means of a strictly juvenile apparatus on the larval legs (Figs. 11-13). Passalids live in dense colonies, and stridulate almost continually. The adults guard, feed, and otherwise care for their offspring from egg to adult (cf. Miller, 1931; Ohaus, 1900). Colonies develop from one or two adults isolated with 5-20 juveniles that are kept by the adult in a compact group. Passalid sounds have evolved somewhat farther than other beetle noises known, as is revealed by the distinct aggressive sound of Popilius disjunctus (Illiger) (Fig. 12), which Mr. William Hebb and Dr. Thomas J. Walker at the University of Florida (personal communication) first heard and tape-recorded. Subsequently Alexander recorded it from Florida and North Carolina beetles just brought in from the field. Hebb and Walker heard it produced by an adult brought into the laboratory during spring (1960) when individual broods of young larvae were present in the field with one or both parents. We heard it in fall (1960) when only adults and pupae were present, caged together in large numbers. Always it is produced by an aggressor during fighting. The stridulator advances, biting at the other beetle, rooting him about with the head, and sometimes lifting him into the air after seizing some appendage with the mandibles. We have seen reciprocal aggression with aggressive stridulation only once, although the fights were sometimes violent, and once a nonreciprocating beetle lost an appendage. One of the aggressive beetles in our cages returned three times to the same crevice and took up the same stance after attacking beetles passing near it, suggesting some form of territoriality. 


\section{P L A T E I X}

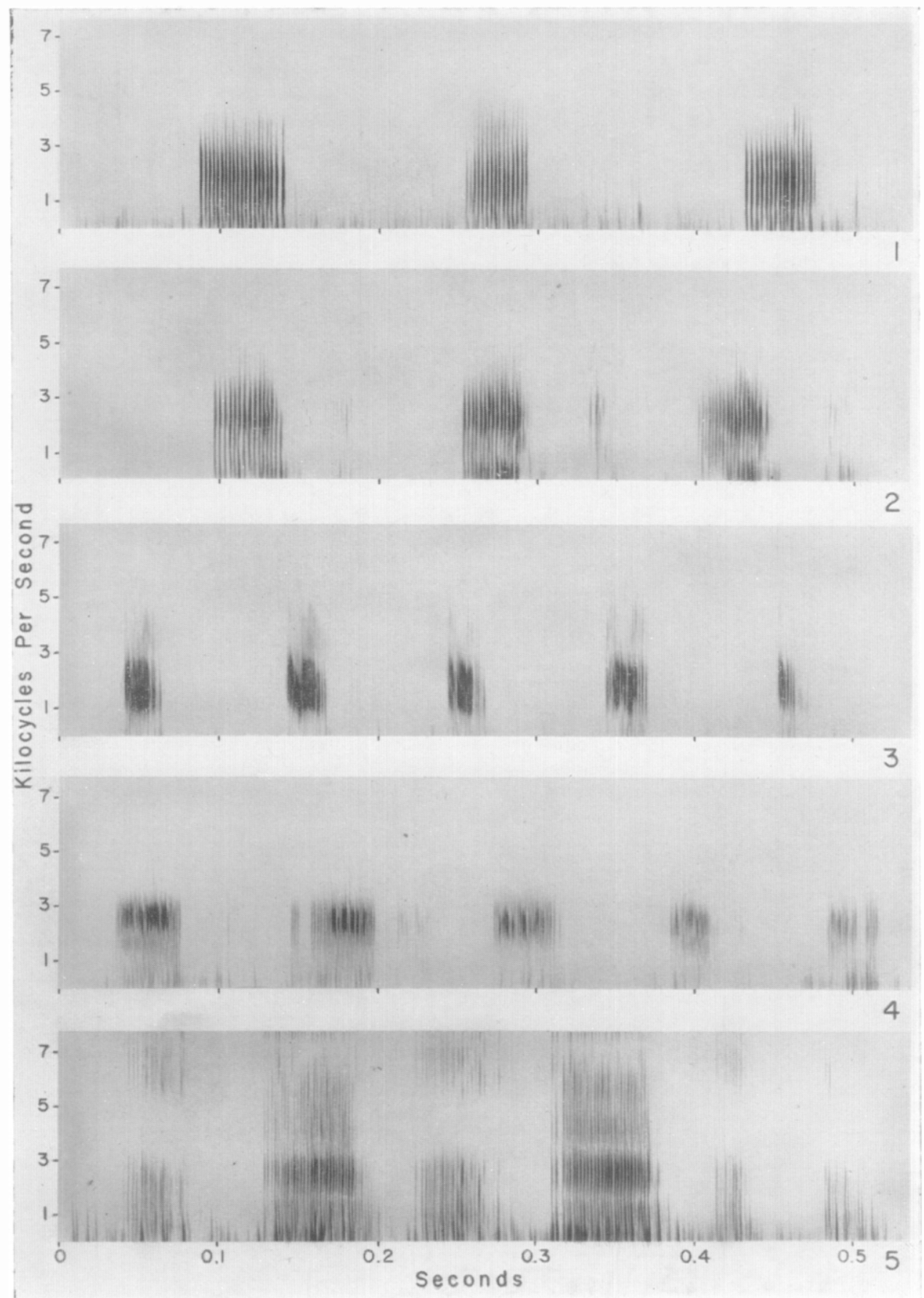

Figs. 1-5. Audiospectrographs of sounds of Trox species (Trogidae): Fig. 1. T. suberosus Fabricius, "spontaneous" stridulation of an adult in a burrow, $61^{\circ} \mathrm{F}$; Fig. 2. T.suberosus, disturbed adult, $70^{\circ} \mathrm{F}$.; Fig. 3. $T$. variolatus Melsheimer, disturbed adult, $80^{\circ}-85^{\circ} \mathrm{F}$.; Fig. 4. T. unistriatus Beauvois, disturbed adult, $80^{\circ}-85^{\circ} \mathrm{F}$.; Fig. 5. T.capillaris Say, disturbed adult, $80^{\circ}-85^{\circ} \mathrm{F}$. 
A NIMAL BEHAVIOUR, XI, 1

P L A T E X

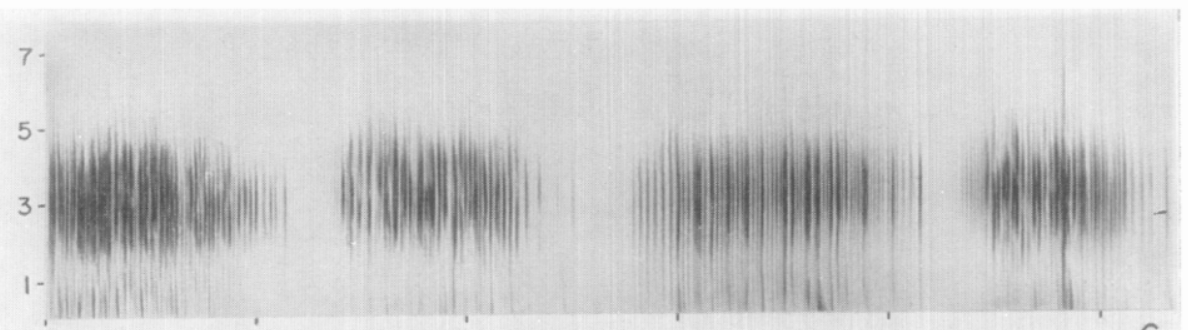

6
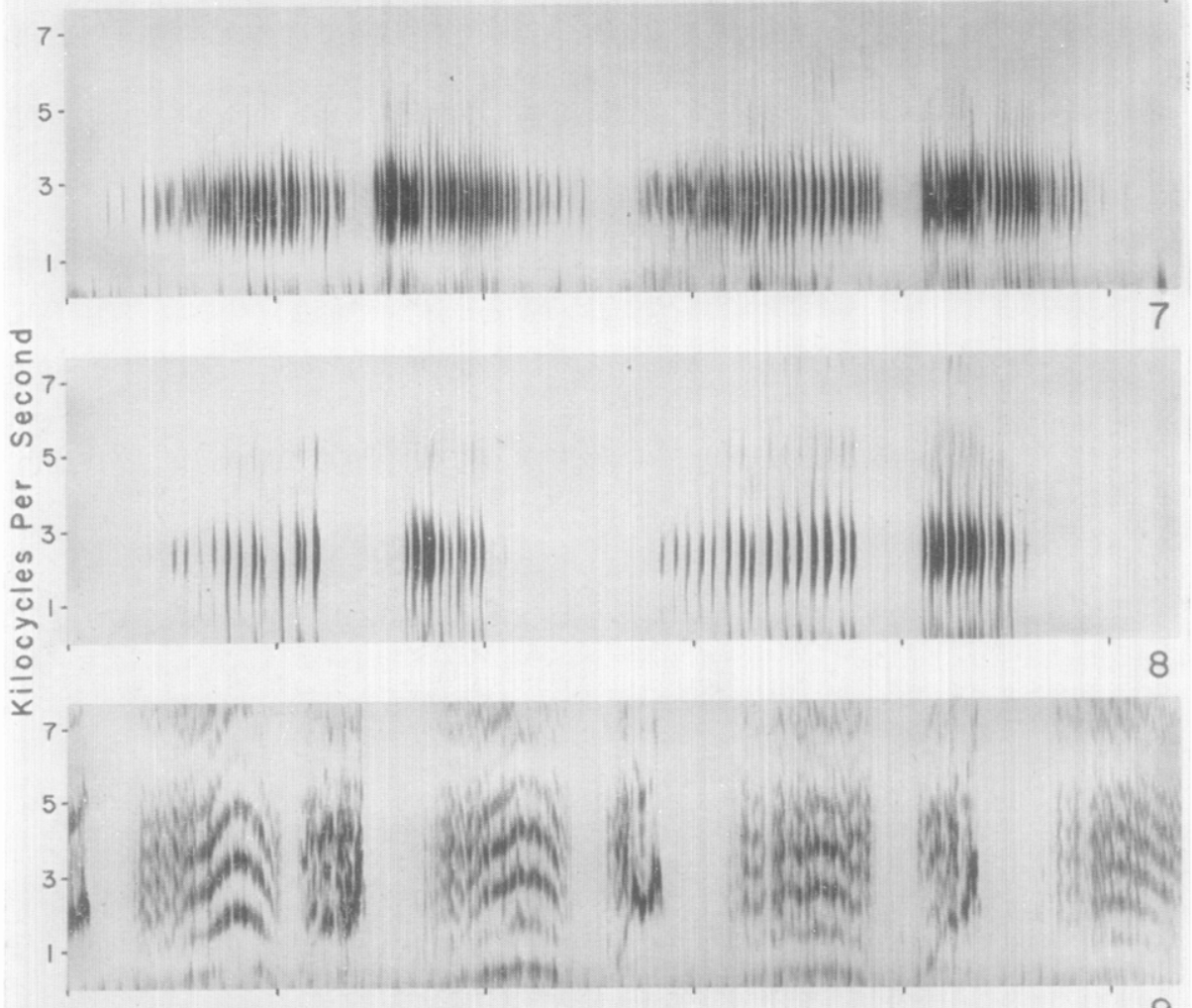

9

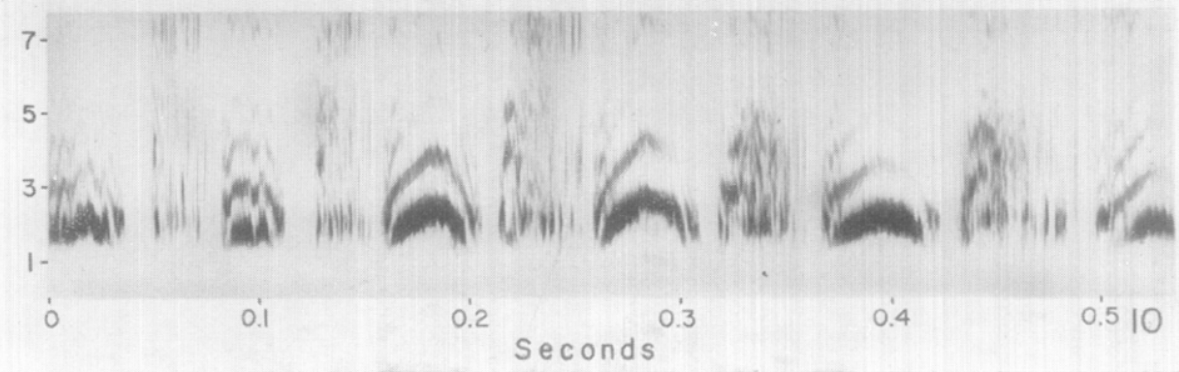

Figs. 6-10. Audiospectrographs of disturbance sounds of adult Scarabaeidae (Geotrupinae) and Cerambycidae: Fig. 6, Geotrupes splendidus (Fabricius) (Geotrupinae), $80^{\circ}-85^{\circ} \mathrm{F}$; F Fig. 7, G. blackburnii (Fabricius), $80^{\circ}-85^{\circ} \mathrm{F}$.; Fig. 8, G. semiopacus Jekel, $80^{\circ}-85^{\circ} \mathrm{F}$.; Fig. 9, Tetraopes tetraophthalmus (Forster) (Cerambycidae), $83^{\circ} \mathrm{F}$; Fig. 10, T. femoratus LeConte, $85^{\circ} \mathrm{F}$. 


\section{PLATE X 1}
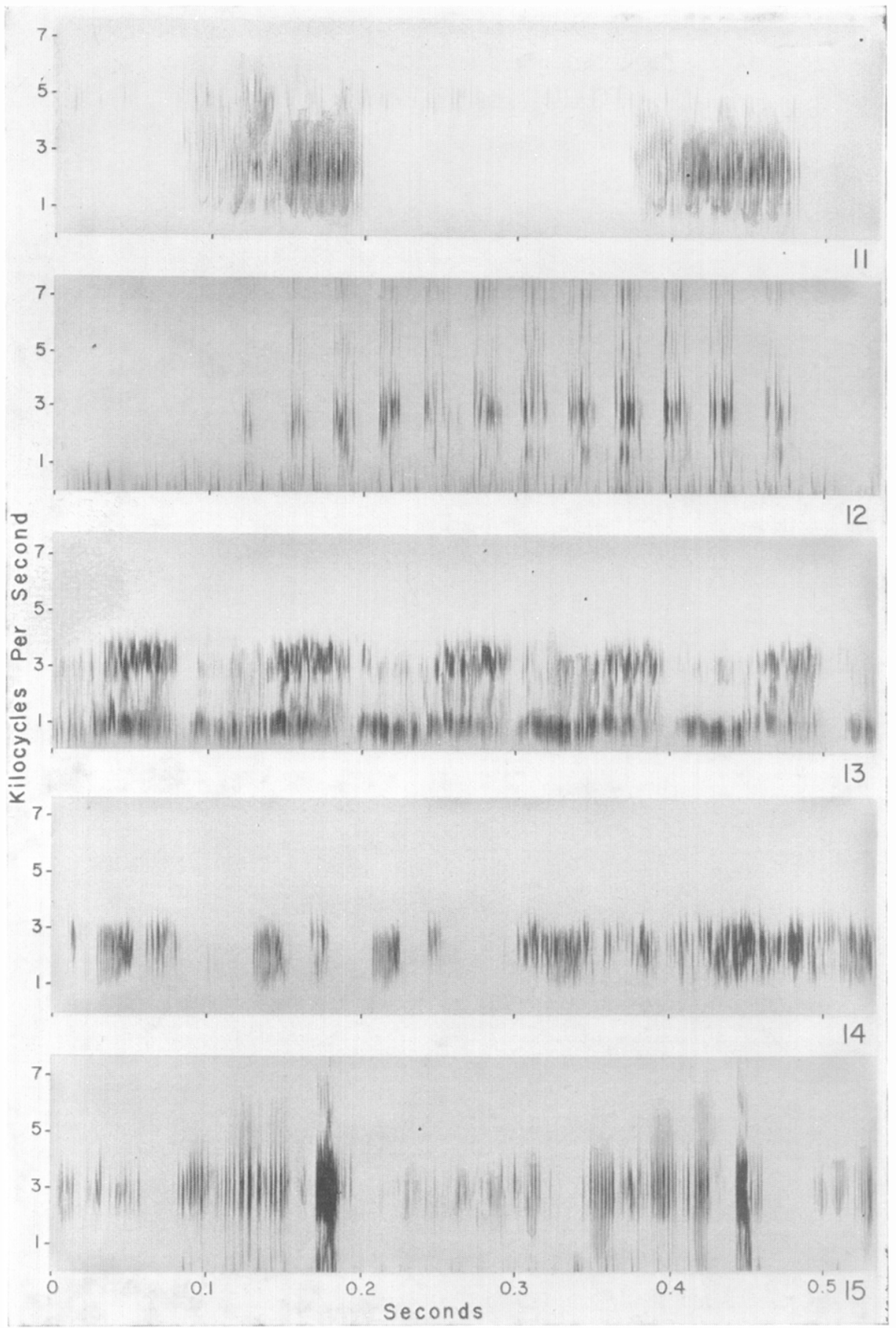

Figs. 11-15. Audiospectrographs of sounds of Passalidae and Scarabaeidae (Acanthocerinae, Aphodiinae): Fig. 11, Popilius disjunctus (Illiger) (Passalidae), disturbed adult, $74^{\circ} \mathrm{F}$. (high-pitched sound is cricket in background); Fig. 12, $P$. disjunctus, aggressive adult, $76^{\circ}{ }^{\circ}$.; Fig. 13, $P$. disjunctus, disturbed larva, $74^{\circ} \mathrm{F}$.; Fig. 14, Cloeotus aphodioides (Illiger) (Acanthocerinae), disturbed adult, $80^{\circ}-85^{\circ} \mathrm{F}$; Fig. 15, Aphodius fossor (Linnaeus) (Aphodiinae), disturbed adult, $80^{\circ}-85^{\circ} \mathrm{F}$. 
On another occasion, fighting was induced several times in succession in two adults in a pan. When placed in a head-on position, the two individuals moved together and antennated each other. After a short time in this position, one beetle (the same each time) suddenly seized the other with its mouthparts and wrenched violently upwards, sideways, and backward. The other beetle in each case lowered its body and stood motionless afterward.

It is interesting that the aggressive sound of Popilius structurally resembles a second noise ("purring") recorded for Tetraopes tetraophthalmus (Forster), and bears essentially the same structural relationship to the disturbance squeak- ing of the species as the second noise of Tetraopes does (compare Figs. 11, 12, this paper, with Figs. 12, 13, Alexander, 1957). However, there is no evidence that the "purring" of Tetraopes is aggressive in function.

Adult passalid beetles produce noises apparently identical to their disturbance squawks when attacked by other beetles and when they come into brief antennal contact with one another while moving about a crowded cage. The adults of Cloeotus aphodioides (Illiger) (Scarabaeidae: Acanthocerinae) make a similar noise when caged together (Fig. 14). Eventually they congregate into a compact ball in the darkest corner of the cage, there continuing to move about and stridulate so that the squirming mass of beetles emits a steady, shrill chatter. In the field these beetles are found in dense clusters under bark.

The disturbance squeaking of both adult and larval passalid beetles has often been discussed, but neither the aggressive nor the "contact" situation-rarely observed because of the specific 'stimuli necessary for their release-has been mentioned previously. No one has yet heard a special adult sound resulting from contact with the larvae, though there surely must be at least one.

\section{Disturbance Stridulations in Congeneric, Sympatric Species}

Many of the beetles known to stridulate upon disturbance inhabit restricted, temporary niches, such as dung, carrion, bracket fungi, and decaying logs, and many of them are also rudimentarily social (Passalidae, Trogidae, Geotrupinae, Coprinae), remaining with the larvae and guarding and caring for them in various ways. The sounds of all these beetles are too soft to operate at
Figs. 16-19. Trox suberosus Fab.: Fig. 16, dorsal view of adult $q$ with elytra removed, showing folded wings in situ and position of the plegmatium; Fig. 17, ventral view of the elytra (circle indicates portion enlarged in Fig. 19); Fig. 18, cross section of the elytra in the area shown by the circle; Fig. 19, enlarged portion of the elytra showing position of the file and the individual teeth. 
very great distances, but in addition to the obvious possibilities in parent-offspring interactions, they could function in several fashions among adults in close proximity. For example, several species of Trox or Geotrupes can be found in the same pile of dung or carrion. In such a mixed population, individuals of the same species might through stridulation find one another and stay together, repel individuals of other species, or stimulate courtship and copulatory activities in con-specific individuals. Repellent stridulation (disturbance reactions?) would be expected to retain or evolve toward non-specificity in the eliciting stimuli; stridulations causing copulation movements should evolve toward specificity in the eliciting stimuli; and congregational stridulations should evolve toward detachment from specific external elicitation. In the last two cases there should be evolution toward species-specificity in the nature of the signals themselves; in the first case this would carry no apparent advantage.

Among our tape recordings of beetles, we have searched with doubtful success among groups of closely related species living together for the beginnings of the three evolutionary directions suggested above. The milkweed beetles, Tetraopes tetraophthalmus (Forster) and $T$. femoratus LeConte (Cerambycidae), occur together on the same plants and are adult at the same times. These species both stridulate readily at the slightest disturbance and terminate the reaction immediately when the stimulus stops; they also show little species specificity in the nature of their squeaking sounds (Figs. 9-10).* All of these characteristics suggest that their sounds are primarily non-specific disturbance reactions.

Figs. 3-5 compare the disturbance sounds of three Trox species (Trogidae) found together as adults in various combinations in owl pellets, carrion, and the like. The sounds of the three species differ in toothstrike rate and pulse length, and in the only Trox species heard in the field- $T$. suberosus - the long-continued nature of the signal indicates divorcement from the eliciting stimulus. These attributes suggest congregational functions.

The third possibility-stimulation to courtship or copulation through stridulatory sounds

\footnotetext{
*In each case where audiospectrographs are presented for comparison, we have used examples that are as nearly alike as we could find. Low frequency markse.g. along the bottom of figs. 1, 5, 7, 9, 12-are background noises.
}

made upon contact between conspecific males and females-is even more difficult to suggest. Perhaps the three species of Geotrupes (Scarabaeidae) whose sounds are shown in Figs. 6-8 represent such a case. Stridulation in these species is not so easily elicited by disturbance. Some individuals could not be induced to stridulate at all, and others stridulated only when a front leg was jerked vigorously with forceps. There is no tendency for stridulation to continue after the disturbance has ceased, and although the sounds differ among species, they are not as distinct as those of Trox species. In central Ohio these three species of Geotrupes are commonly found living together in the same pile of dung.

\section{Discussion}

The paucity of specific information as to their effects makes it tempting to discount the significance of the countless soft sounds produced by disturbed insects. But there was a period when misguidedly parsimonious biologists for the same reason repeatedly pronounced accidental and meaningless even the elaborate performance of Orthoptera and Cicadidae. The behaviour of beetles is almost totally unexplored, and situations in which those species that produce sounds upon disturbance might also stridulate in connection with sexual or social behaviour may be rarely observed. Actually, even intense orthopteran sounds, which seem a veritable bedlam to those familiar with them, go completely unnoticed by most people, and it is certain that we would not have noticed the sound of Trox suberosus-though it was audible several yards away-if we had not been listening continually for the stridulations of nocturnal Orthoptera.

Obviously the disturbance stridulations of beetles have little taxonomic significance. This is not unexpected because they operate only at close range after the individuals involved have been brought together by some other kind of stimulation. However, the rudimentary nature of acoustical behaviour in beetles-coupled with the great number and variety of species and systems involved-makes this kind of behaviour in these particular animals an appropriate subject for the study of evolutionary direction in the early elaboration of communicative systems. 


\section{R E F E R E N C ES}

Alexander, R. D. (1957). Sound production and associated behavior in insects. Ohio J. Sci., 57, 2, 101113 , 13 figs., 1 text fig.

Alexander, R. D. (1960). Sound communication in Orthoptera and Cicadidae. In: Animal Sounds and Communication (Lanyon \& Tavolga, ed.). A.I.B.S. Publ., 7, 38-92, 16 figs., 5 recordings.

Arrow, G. J. (1904). Sound-production in the lamellicorn beetles. Trans. ent. Soc. London, 1904, 709-751, $1 \mathrm{pl}$

Frings, H. \& Frings, M. (1960). Sound production and sound reception by insects: a bibliography. Univ. Park, Penn: Penn. State Univ. Press.

Huber, F. (1960). Untersuchungen über die Function des Zentral Nerven-systems und inbesondere des
Gehirnes bei der Fortbewegung und der Lauterzeugung der Grillen. $Z$. vergl. Physiol., 44, 60132, 38 figs., 8 tab.

Liles, M. P. (1956). A study of the life history of the forked fungus beetle, Bolitotherus cornutus (Panzer) (Coleoptera:- Tenebrionidae). Ohio $J$. Sci., 56, 3, 329-337, 4 figs., 1 tab.

Miller, W. C. (1931). Some observations on the habits of Passalus cornutus (Coleoptera). Ohio J. Sci., 31, 266.

Ohaus, F. (1900). (On the stridulation and social life of Passalus cornutus Fab.). Stett. ent. Z., 61, 164.

Sharp, D. (1897). On the stridulatory organs of Trox. Ent. monthly Mag., 33, 206-207.

(Accepted for publication 28th June, 1962 Ms. number: 282). 